Revista Iberoamericana. Vol. LXVI, Núm. 193, Octubre-Diciembre 2000, 863-876

\title{
EL CONTRAPUNTEO LATINO ENTRE EL INGLÉS Y EL ESPAÑOL: NOTAS PARA UNA NUEVA EDUCACIÓN SENTIMENTAL
}

POR

DoRIS SOMMER

Harvard University

— No bueno, dijo el doctor frunciendo el ceño, cuando entró con los rayos X de Barbarita. —Le pidió a Mima: Pregúntele si ha tenido TB. (Sigla en inglés para la tuberculosis).

—-Mima se volvió a Barbarita: "Dice que si tienes una televisión".

-Dile que sí, pero que en La Habana. En Miami, no. Pero mi hija tiene una aquí.

- Mima le dice al doctor: Ella dice que tuvo una TV en Cuba, no en Miami, pero que su hija tiene TV aquí.

—En ese caso, tenemos que hacerle a su hija una prueba de TB también.

- Mima tradujo: Dice que necesita hacerle una prueba a la televisión de tu hija para ver si funciona, de otro modo no podrás conseguir tu tarjeta de residente.

— ¿Por qué la televisión? preguntó Barbarita desconcertada.

- ¿Cuántas veces te he dicho que necesitábamos comprar una televisión? ¿Es que no te enteras, Barbarita? Esto es América.

Roberto Fernández, Wrong Channel

—Pregunte al acusado si robó el caballo.

—El juez quiere saber si usted robó el caballo.

— ¿Yo robé un caballo?

-El acusado dice que robó un caballo.

-Pregúntele al acusado si necesitaba un caballo.

-El juez quiere saber si necesitaba un caballo.

- ¿Yo necesitaba un caballo?

-El acusado dice que necesitaba un caballo.

-Pregúntele por qué lo necesitaba.

-El juez quiere saber por qué usted necesitaba un caballo.

- ¿Yo?, ¿Un caballo? Oyf kapures (Para un sacrificio = para nada, jamás lo he querido)

lo necesité

-Dice que necesitaba el caballo para un ritual.

Chiste judíoamericano

Estos chistes funcionan en inglés, pero no se quedan dentro de sus límites; lo estiran y le abren brechas al forzar una confrontación, o una convivencia, con otros códigos. De esta manera, revelan la insuficiencia del lenguaje en un espacio y un momento de incontenibles inmigraciones y de prácticas políticas que parten muchas veces de identificaciones culturales particulares. Su limitación no es que se trate del inglés y no de otra lengua. Al 
contrario, quizás, ya que el inglés se enorgullece (con considerable razón) de ser amplio, flexible, heredero mestizo de una familia bicultural, de madre teutónica y de padre romance. Mi “lingua Franca, or mixed language”, es el mote, afectuoso y agradecido, que le pone Sir Walter Scott en Ivanhoe (41). ${ }^{1}$ La insuficiencia a que me refiero es simplemente que es un idioma en vez de dos.

La observación de la convivencia de gentes y de códigos es sencilla e ineludible, aunque la respuesta no será fácil. Necesitará una fundamental re-educación sentimental que aprecie y valorice la biculturalidad, en vez de convertirla en materia prima para el crisol de “lo nacional”, llámese melting pot, raza cósmica, o transculturación. Hace un siglo y medio, el reto para la literatura en América Latina era muy distinto. Se trataba de formar países, convertir súbditos, identificados por sus “castas” y acostumbrados o a mandar o a someterse, en ciudadanos que compartieran libremente un país y una cultura, ciudadanos que se amaran mutuamente a pesar de las diferencias raciales, económicas y regionales que habían obstaculizado sus amores durante la Colonia. El reto urgente era reemplazar los gustos y valores avasalladores de la Colonia, por otros deseos y expectativas modernos, aunque era necesario un pausado proceso de entrenamiento, una conversión del alma a través de ejercicios espirituales. Se dieron, mayormente a través de los folletines semanales, donde los amoríos entre sectores antagónicos entrenaron a los lectores en la identificación con un imaginario colectivo.

El logro monumental de las novelas nacionales escritas por próceres y políticos, representa hoy un baluarte contra la flexibilidad democratizante, por una de esas paradojas que se dan cuando una buena idea es confundida con un ideal inmutable. La educación sentimental era, entonces, mucho más que el título de una novela decimonónica. Era el programa de todo el género. ${ }^{2}$ En Flaubert, la educación describe un conflicto entre aficiones erótico-artísticas y deseos vulgares de bienestar burgués. Las alternativas son cacofónicas en ese momento histórico europeo, cuando el noble aire del "dolce fare niente" es interrumpido por la marcha mercantil del "laissez-faire”. Ahí la vaga melodía sufre un síncope [término también médico para la muerte aparente, pasajera]. Y las novelas liberales americanas la rematan.

Pero hoy, en la tardía modernidad o posmodernidad, hace falta una re-educación, esta vez para valorizar las diferencias que habíamos querido reducir con la antigua educación republicana. Esta diferencia está a la vista de casi todos, ahora que el tejido de las sociedades modernas descubre espacios deshilvanados, y que otras sociedades por mucho tiempo en vías de alcanzar la coherencia moderna — cual Sísifos asomados en distintos puntos de la cordillera global — reconocen que el "lag-time” entre la actualidad y la meta es estructural,

\footnotetext{
${ }^{1}$ Dice también Walter Scott: "Still, however, the necessary intercourse between the lords of the soil, and those oppressed inferior beings by whom that soil was cultivated, occasioned the gradual formation of a dialect, compounded betwixt the French and the Anglo-Saxon, in which they could render themselves mutually intelligible to each other; and from this necessity arose by degrees the structure of our present English language, in which the speech of the victors and the vanquished have been so happily blended together; and which has since been so richly improved by importations from the classical languages, and from those spoken by the southern nations of Europe” (30).

${ }^{2}$ Véase una versión cínica de esta observación, en Bourdieu.
} 
repetido, infranqueable. ${ }^{3}$ Hoy vivimos normalmente la asimetría, con más de un lenguaje y en más de una cultura, muchas veces con una lingua franca y otra particular. Quiero decir que la "doble conciencia” es, en la actualidad, una condición saludable, aunque se había diagnosticado como el mal del sujeto minoritario, el obstáculo a la formación personal y colectiva de los que enfrentan la imposibilidad de compaginar los papeles del ciudadano ideal y el de racialmente "raro", de americano y de negro, en la famosa formulación de W. E. B. Du Bois en Souls of Black Folk (1903).

El corolario a esta curación en salud es un agradecimiento. Porque gracias a este biculturalismo (bilingüismo, en su forma más perceptible) el ciudadano llega a tolerarse a sí mismo, en las contradicciones culturales que no dejan de surgir hasta en la aparente homogeneidad de un lenguaje, y llega también a tolerar a los conciudadanos - heterogéneosque comparten los espacios que llamamos todavía —un tanto anacrónicamente- naciones. En vez de aglutinar distintas gentes en una nación coherente, habrá que flexibilizar el espíritu nacional, para tolerar los dioses y deseos en conflicto. El ciudadano de hoy, si no es bi-cultural y hasta bi-nacional, convive en un espacio nacional con los que sí lo son (diez países americanos, hasta el momento, reconocen la doble ciudadanía y los lazos con la primera patria que continúan después de la "naturalización” en otra ${ }^{4}$ ). Y una nueva educación sentimental, a través de las artes bilingües, por ejemplo, habrá de convertir el ideal cultural unísono de la patria en un democrático contrapunteo de diferencias (lingüísticas, étnicas, sexuales) dentro de uno, y entre uno y otro. Si las diferencias se provocan en una angustiada “doble conciencia”, para el sujeto bi-cultural también crean acordes. De los dos depende la música digna de llamarse democrática en la posmodernidad.

En el presente, y en el futuro previsible, uno más uno son realmente dos, y no un tercer término singular, dialécticamente depurado de los conflictos entre distintos códigos. Esa había sido la meta y por lo tanto el motor de los programas modernizantes (léase también nacionales) en las Américas así como en Europa. En términos muy generales, el esfuerzo ha sido por homogeneizar la cultura, tanto del pueblo identificado con un país, como —a fortiori- del paisano individual. ${ }^{5}$ Tal proceso prometía acabar con las identificaciones particulares, históricamente hostiles entre sí, para desarrollar una ciudadanía igualitaria, basada en una (sola) cultura nacional donde todos hablaran el mismo idioma. Por eso, explicaba Benedict Anderson en su ya clásico ensayo de 1983, que "la comunidad imaginada” merecía el apoyo y la adhesión de gente progresista durante el siglo XVIII, el XIX, y también durante las guerras de liberación nacional durante el siglo XX. Todavía hoy, frente a propuestas de un cosmopolitismo desarraigado, capaz de intervenir irresponsablemente en los países de origen, Anderson afirma su fe en la moral nacionalista que asume responsabilidades colectivas y es capaz de sentir vergüenza ante errores y abusos

\footnotetext{
${ }^{3}$ Concepto acuñado por Bhaba.

${ }^{4}$ Jones-Correa, indica: "The bigamy analogy comes up a lot among critics of dual nationality” (19) which suggests the nineteenth century "Foundational Fictions" motif of sliding from Eros to Polis that I considered in the 1991 book.

${ }^{5}$ Véase Degregori, respecto al Perú, caso dramático de esta insistencia oficial en un país homogéneo y de propuestas alternativas hoy.
} 
cometidos en nombre de la nación. ${ }^{6}$ Se entiende su reparo respecto a "long-distance nationalism”, más que nada porque supone el ideal de pertenencia unívoca elaborado en la (corta) época moderna. Anterior y posteriormente, las pertenencias suelen ser dobles, o múltiples, querámoslo o no. La pregunta es cómo intervenir en esta arena movediza de pertenencias a veces impertinentes. Anderson quisiera que volviéramos a nuestras casas que exigirían la responsabilidad por el prójimo, mientras que otros queremos dar cuenta de que tal responsabilidad a veces exige que nos quedemos desplazados, como irritantes culturales que obliguen y así ayuden a construir espacios tolerantes.

Es notable que los modernos discursos académicos difícilmente se dejan irritar por la convivencia cotidiana de una lengua particular junto con la lengua oficial. Parece ser que el sueño homogeneizador de la modernidad se realiza, tautológicamente, en las disciplinas monolingües que parten de los valores de esta anhelada modernidad. Ni la literatura, ni la estética suelen considerar los juegos bilingües; la filosofía del lenguaje suele asumir el uso de un solo código, así como el psicoanálisis, el humor, y la política, aunque esta última comienza a teorizar los “derechos culturales” particulares. Mi modesto propósito en las siguientes páginas es llamar la atención a esta general negación, y sugerir las maneras en que varios campos intelectuales se pueden ensanchar, si se asoman a la cerca del monolingüismo y se atreven a cruzarla.

Los chistes bilingües terminan mofándose tanto de los monolingües nativos como de los otros, recién llegados. Saber un solo idioma equivale a perder el chiste, o una curación, o un proceso jurídico. Por un lado, entonces, el blanco es el escucha monolingüe, que muchas veces se entera de haber sido el motivo de la risa, y lo resiente. Pero, por otro lado, el partícipe ridiculizado es el mismo sujeto bilingüe (o como Freud diría, “alguien de su nación”), alguien capaz de contar el chiste y entenderlo inmediatamente. De modo que éste es un género reflexivo, tiene un efecto de boomerang (está dirigido a la persona monolingüe, que no encontrará el chiste gracioso), pero en última instancia se dirige al mismo cuentachistes para burlarse de sí mismo con un ligero desdén. Después de todo, este cuenta-chistes pertenece a una clase de nuevos estadounidenses cuyo precario inglés les mantiene esperando por doctores que aprueban visados y preocupados por abogados que puedan mal representarlos en el juzgado. El precio a pagar puede ser muy alto, como ocurre en la escena climática de la película chicana, The Ballad of Gregorio Cortez. La interrogación en inglés y español, mal traducida y representada sin subtítulos, termina violentamente, cuando el "relajo" hace reír a su hermano y es malinterpretado como resistencia a la ley.?

Hay chistes que están destinados a perder: denigran a sus contadores, y sin embargo, a estos les gusta contarlos. ¿Por qué?, ¿ es suficientemente divertido observar que el hablante monolingüe queda fuera del juego? Algunas posibles respuestas nos llevarán desde las especulaciones de Freud sobre los chistes como las formas más sociales del humor, hasta algo nuevo, "la estética del bilingüismo”, un espacio teórico que necesita ser nombrado y

\footnotetext{
${ }^{6}$ Anderson pone como ejemplo la destrucción de la mezquita en la India, por el movimiento hindú extremista, fundado por correligionarios radicados fuera del país.

${ }^{7}$ The Ballad of Gregorio Cortez (1983), con Edward Olmos, dirigida por Robert Young y producida Moctesuma Esparza, con el apoyo del Robert Redford's Sundance Institute, PBS, y la National Endowment for the Arts.
} 
acotado. Este nuevo campo reconoce como propio el tipo de refinamiento específico a los juegos idiomáticos que operan en más de un código. Y entre Freud y la estética del bilingüismo, pasando por los juegos monolingües de Wittgenstein, nos detendremos ante la incómoda paradoja que me incita a búsquedas nuevas. Esta paradoja consiste en que el refinamiento bilingüe es muchas veces autodespectivo - ya bien amargo, ya bien filosóficoy hasta puede comunicar el deseo por la simplicidad graciosa de la cultura burlada.

[...] admiras su eficacia, sus comodidades, su higiene, su poder; y más te duele saber que por más que lo intentes, no puedes ser como ellos. Porque después de todo, di: tu visión de las cosas, en tus peores o en tus mejores momentos, ha sido tan simplista como la de ellos. Nunca. (Carlos Fuentes 32-33)

No es fácil detenerse aquí, o en cualquier otro sitio incluyendo el amor — dice Stanley Cavell, para quien la modernidad consiste en una perdida trágica de nuestra capacidad para poner atención (Carvell, 181). Esa misma modernidad aconseja superar el bi-culturalismo, elegir un común denominador y convertir dos lenguas en una. Este consejo es análogo a recomendar el duelo para curar la melancolía y además hace parte de esa receta, entendida en términos colectivos y culturales: es necesario dejar el peso de las relaciones pasadas, liberarse del fantasma del ayer que amenaza nuestra independencia emocional.

"Es hora de olvidar el pasado, de hacer el duelo necesario para que la vida resuma su marcha”. Según un amigo, David Lloyd, éste es el higiénico consejo de los ingleses a un pueblo vecino, tradicionalmente católico, por muchos años subalterno, militantemente premoderno, reacio a esta receta para la salud mental. Me refiero a los irlandeses, cuya agresiva melancolía es una afrenta a la buena salud inglesa. Los irlandeses prefieren cargar la terrible memoria de los vejámenes sufridos bajo el dominio inglés, el hambre, la humillación, las masacres, a emprender la ¿cura? del olvido que es también otorgarle la absolución a los ingleses. Robert Southey fue enviado a Brasil a principios del XIX para estudiar su sistema exitoso de trabajo forzado y recomendar mejoras para el manejo de los trabajadores irlandeses. ${ }^{8}$

Hace algo más de un siglo, Ernst Renan explicó una profunda paradoja entre las muchas que hacen parte del nacionalismo europeo, al afirmar que la nación se consolida no por lo que recuerda colectivamente, sino por lo que logra olvidar. Los pueblos olvidados por la Historia (olvidados a causa de las guerras, el hambre, o la subyugación) desafían el consejo del que se sirve el opresor y responden de otra manera: rehusan olvidar los ultrajes que los convirtieron en pueblos oprimidos. Si olvidaran no habría manera de dar cuenta del subdesarrollo y la subalternidad; se tendrían que inventar otras razones, fundamentadas en supuestas deficiencias innatas, de talento, industria o voluntad. La melancolía es, por lo

\footnotetext{
${ }^{8}$ Brasil fue un modelo de convivencia productiva entre las razas. En las palabras de Gilberto Freyre, "Although a perfect intercommunication between its cultural extremes has not been achieved in Brazil — extremes that are still antagonistic and at times explosively so, clashing with one another in such intensely dramatic conflicts as that of Canudos—none-the-less we may congratulate ourselves upon an adjustment of traditions and tendencies that is rare...”. La historiadora brasileña, Miriam Moreira Leite me aclaró que Robert Southey, que buscaba consejos sobre cómo manejar a los irlandeses, nunca llegó hasta el Brasil, sino a Portugal, y que escribió su History of Brazil en Inglaterra.
} 
tanto, una vacuna contra mayores males, es una dosis de tristeza comprensible que no deja lugar a mayores depresiones y así evita estragos intolerables. El chiste es que el mal de uno es también un desafío para los que pretenden curarlo.

FREUD

Freud sabía que los chistes participaban de la melancolía, por lo menos aquellos que más le divertían, como la descripción que Heine hace del Barón Rothschild, quien sienta al pordiosero en su mesa y lo trata exactamente como a su familia, una familia olvidada, muy “famillonaria”. U otro chiste en el que un judío le pregunta al otro: “¿Tomaste un baño?”, y el otro contesta, “¿Por qué, falta alguno?”. Pero melancolía no es un vocablo que Freud hubiera usado para validar el estudio de los procedimientos del chiste wit-work — como complemento al de los procedimientos del sueño- estudio que tenía el objeto de explorar el subconsciente (Freud). La melancolía reprime los circuitos del placer que el chiste libera; una asedia, el otro emancipa; una reconoce la pérdida innombrable, el otro la hace irrumpir con el temblor de la risa.

No insistiré en la carga melancólica del humor bi-cultural ya que la insistencia pondrá a los escépticos a la defensiva de tal manera que se podrían perder el chiste de una teoría freudiana desestabilizando a la otra. En cambio, me conformaré con señalar un síntoma de la inestable contradicción entre alegría y melancolía en la medida en que hace travesuras con sus teorías. Como parte general de su proyecto para describir las propiedades universales y los mecanismos de la psicología y, por consiguiente, para de-patologizar el grupo considerado neurótico, a saber, los judíos, Freud considera el chiste como un rasgo universal de la expresión humana. Ciertamente, él no fue el primero en dignificar el chiste haciéndolo objeto de estudios (reconocidas referencias datan de Henri Bergson, Helbert Spencer y otros), pero Freud le dio una importancia central para su proyecto general.

Los numerosos chistes que Freud disfruta contando, lo llevan a concluir que estos funcionan como los sueños, de tal modo que estudiar los chistes es otra ruta al inconsciente. Como los sueños, los chistes a menudo se sirven de las técnicas de condensación y desplazamiento que producen un aparente sin sentido, signos en realidad de un deseo disimulado o un algo de sabiduría. Según Freud, la gran diferencia entre sueños y chistes consiste en que los primeros son personales (no necesitan ser compartidos, ni siquiera necesitan ser entendidos por el soñador) y el chiste es social, tan social que necesita por lo menos de tres participantes para que funcione. Aún más, los chistes funcionan mejor dentro de sociedades claramente definidas: una cultura nacional o, aún mejor, un subgrupo minoritario con una densa historia de subyugación y frustración. La cultura judía, por ejemplo.

Dice Freud: "No exigimos ninguna patente de nobleza para nuestros ejemplos, ni hacemos preguntas sobre su origen. Nuestro único requisito es que nos hagan reír y que sirvan a nuestros intereses teóricos. Ambas exigencias son satisfechas de manera inmejorable por los chistes judíos” (657).

Un caso especialmente propicio para el humor tendencioso resulta si la crítica de la resistencia interior se dirige contra la propia persona, o más propiamente, contra la persona 
que es objeto de interés, es decir, contra un sujeto compuesto, tal como es la gente de uno. Esta vocación para la autocrítica puede aclarar por qué es que del grupo de chistes que hemos enumerado una gran cantidad de chistes surge de la vida nacional judía. Son historias inventadas por los propios judíos y están dirigidas en contra de las peculiaridades judías. El chiste judío contado por el no-judío es casi siempre mofa brutal en la que el humor se obvia ya que el judío es representado como una figura cómica por el extranjero. Los chistes sobre judíos inventados por los propios judíos conocen las limitaciones y méritos de la cultura propia a la vez que el interés del cuenta-chistes en lo criticado produce la determinación subjetiva del procedimiento humorístico que de otro modo sería difícil de lograr. Incidentalmente, yo no sé de otro grupo de gente que tan abiertamente haga chistes sobre sus propias debilidades (705). [...] La variada y desesperanzada miseria judía aludida en estas historias, me incitó a incluirlas en la categoría del humor tendencioso. (707)

El chiste es universal, pero el judío lo hace mejor que los otros. El chiste funciona como el sueño, pero su dimensión social es determinante: dirige y determina transformaciones inconscientes. Aquí hay una contradicción evidente. Por un lado queda la afirmación de carácter científico y, por el otro lado, queda un grupo, unas circunstancias particulares declaradas como las más propicias. "Todos nosotros somos responsables”, dice Levina apropiándose de Los hermanos Karamazov, "pero yo soy más responsable que el resto”.

Una contradicción es una encrucijada. Ésta en particular nos podría remitir a una empresa deconstructiva en contra de los universales mecanismos y estructuras del inconsciente. O bien, podría invitarnos a evaluar la intrincada relación entre ciencia y circunstancia, estructura predecible y narración confusa. Yo, en cambio, opto por una ruta menos ambiciosa que las anteriores. Mi opción no va muy lejos, más bien se queda con los desvíos inesperados de la teoría. En otras palabras, me parece importante permanecer en la contradicción y contemplar la fascinación de Freud por el humor judío. ¿Por qué le permite constantemente ser el tema central aún a costa de su proyecto científico? Me atrevo a notar una extraordinaria similitud: la travesura de que el humor judío tiene un claro parecido con el humor obsceno que tanto le gusta a Freud. No, no me refiero a la aburrida e irritante asociación entre judíos y chistes verdes; una asociación prácticamente inevitable en la Viena de Freud, donde su libro “científico” sobre el chiste pretende culminar y rematar una pequeña industria de libros judíos de chistes verdes (junto con el auto-odio que teoriza Sander Gilman). Lo que sí me interesa al respecto es una coincidencia estructural entre el pensamiento “científico” y la práctica maliciosa del chiste particularista.

Como en el humor erótico, los chistes judíos (o, de minorías en general) necesitan por lo menos de tres participantes: 1) el emisor del chiste, 2) el objeto sobre el que se hace el chiste (una posible conquista, un miembro de la cultura mayoritaria), y 3) un oyente del chiste, para quien el sujeto hace el chiste. Es una semejanza asombrosa. En ambos casos, el segundo término es prescindible (693). Ni "las mujeres” ni los miembros de la "mayoría” se van a reír; ellos son a duras penas necesarios y una mera referencia a ellos basta. En ambos casos, un choque entre códigos es lo que prepara el chiste. En el primero, un choque entre los deseos del hombre y la resistencia de las mujeres; en el segundo, la divergencia entre una cultura mayoritaria y una minoritaria. El sujeto que emite el chiste y el oyente comparten los mismos presupuestos, mientras que su rehén no. En ningún caso, el objetivo es "ganar” 
(ni seduciendo ni emancipándose de la mayoría). Más bien consiste en humillar a ese segundo término y celebrar la superioridad del emisor y el receptor. Freud nunca hubiera aceptado este punto de vista, el cual puede ser resultado de lo que para algunos será una interpretación excesiva por parte mía de su preferencia por los chistes judíos, su placer por contarlos más allá de las exigencias del texto. Dentro de Freud opera en esos momentos una opción preferencial por su identidad judía, lo que le incita a distanciarse cultural y emocionalmente de los gentiles y, a la vez, constituye un obstáculo para los métodos universales de la ciencia.

El sentido de superioridad se da por supuesto en el humor obsceno, en el que evidentemente, los hombres asumen ventajas sobre las mujeres. Lo que quiero sugerir es que una asimetría similar funciona en los chistes de minorías, en los que la autoridad está a menudo del lado de la subalternidad. Si la autoridad es simplemente asumida de manera natural o si está construida por las mismas bromas depende de las circunstancias. Pero la descarga de energía reprimida en la gente que ha tenido que aprender actitudes de humildad o enfado hace más llevadera la carga cotidiana. La liberación es un doble placer para el oyente: por un lado está la satisfacción intelectual al entender la broma; por otro, la alegría maliciosa porque el otro (el mayoritario) no la entiende. ¿Qué es lo que este segundo participante no entiende? Generalmente el hecho de que se ha creado un chiste, mediante una relación tripartita que lo ha utilizado como accesorio. Esta persona puede reírse también, animada por la risa general, pero confundiría el chiste "wit" con una forma de humor más simple "lo cómico" que requiere sólo de dos participantes. El error está en imaginarse que uno es la audiencia ideal de la broma, en vez de saberse su blanco. Claro, la gente puede pasar de una situación a otra, puede aprender códigos multiculturales y llegar a ser el agente de la broma en lugar del objetivo. Pero sin los presupuestos compartidos, concretamente, sin la expectativa de que un bromista minoritario puede ser lo suficientemente sofisticado para hacer un chiste, el blanco de la broma puede aún descender a una posición más ridícula, ya que la risa tonta de la persona sobre la que se hace el chiste sólo incrementa el nivel de hilaridad del chiste.

La alegría del que cae en la cuenta, frente a la ignorancia del otro, ¿es un tipo de compensación por lo que nos hace falta? ¿Sexo? ¿Poder? ¿Dinero, educación, trabajo, respeto? Tal vez. En todo caso, estos bienes pueden ser considerados tan irrisorios e indignos como el sistema que los sustenta. El chiste de minorías en último término se revierte contra sí mismo, juega para perder; de modo que la derrota parece inevitable y más digna que la victoria. Me vienen a la cabeza libros latinoamericanos, tales como Manual de perdedores, Perder es un método (Amar Sánchez), no porque estén escritos por minorías, sino porque encaran una globalización rampante. Freud se cuestiona esto mismo repetidamente, al considerar cuán autodespreciable es el humor judío.

El chiste puede invertir la asimetría dictada por el dinero, poder y respeto público, por lo menos durante el momento en que la risa hace estragos. Y el desequilibrio es especialmente vulnerable en el más claro caso del chiste bi-cultural: la broma bilingüe. Cuando el monolingüe cree entender la esencia de la historia, lo que realmente comprende puede ser un absurdo, un sin sentido. ¿No es esto lo que le sucede al doctor de la anécdota de Roberto Fernández, cuando no percibe la ambigüedad entre TB y TV pero presume pronunciar las 
palabras en un español incorrecto para aparentar un mínimo de competencia? ¿No es eso lo que le sucede al juez en el chiste sobre el caballo cuando escucha el "Oyf kapures" del acusado como si fuera una ridiculización del "oy vey" desesperado, en lugar del rechazo figurado de culpa? Y ¿no es acaso lo que sucedió a Sherif quien pensó haber entendido lo que significaba un simple NO en el informe detallado y cortés de Gregorio Cortez?

Freud no ofrece ningún ejemplo de un chiste en lengua Yiddish; es quizás el único género que omite. A lo mejor entendió que los juegos lingüísticos excluyentes son incompatibles con su proyecto universalista. Además del alemán, Freud sólo usa el francés (y asume que todo lector instruido lo entiende) o el italiano (el cual traduce entre paréntesis). Pero sobre todo, Freud evita las bromas populares que malamente traducen la recalcitrante y particularista especie de alemán que usaba su madre, Yiddish, a la versión hegemónica.

La excursión de Freud al inconsciente es prescindible para el chiste bilingüe. Sin este viaje, Freud se queda sin ciencia; y el humor bilingüe no lo requiere. Para Freud, el chiste necesita zambullirse en el inconsciente hacia una asociación reprimida. Sin este chapuzón, la luz de la inspiración que se traduce en pérdida de control, no hay chiste. Y una clara diferencia entre el chiste y lo cómico es que la comedia puede permanecer en el nivel consciente; realiza conexiones entre consciente y "preconsciente", algo familiar pero olvidado, en lugar de reprimido. No obstante, me atrevo a opinar en contra de Freud: una buena broma bilingüe no depende de asociaciones reprimidas; al contrario, pesca palabras en un río perfectamente visible y compartido de un lenguaje alternativo. Es sutil, y sin embargo claramente viable, sofisticado y democrático. A Freud, seguramente, le hubiera desconcertado tanto cruce desbordante de fronteras que consiguen esquivar y rodear al inconsciente. ¿Qué ciencia queda vigente ante tanta travesura?

\section{WiTTGENSTEIN}

Por alguna razón, esta doble satisfacción bilingüe no ha sido tema literario. Ni la estética tradicional (incluyendo la retórica), ni la filosofía del lenguaje ha salido del monolingüismo. Lo bilingüe es, muchas veces, un problema político, pedagógico, casi una patología para muchos países industrializados. Sin embargo, no ha llegado a ser un campo cultural, aunque su cultivo podría seguir lo que aconsejó Wittgenstein para las patologías filosóficas: no curarlas, sólo describir sus usos normales para poder ver lo que son. Lo que es normal, en los juegos bilingües, dice Ana Celia Zentella, sociolingüista del barrio de los puertorriqueños en Nueva York, es la virtuosidad creativa. Ella compara estos juegos bilingües con el baloncesto o el bailar salsa. Son expresiones de arte colectivo, vehículo para la solidaridad al igual que un espacio para la creatividad personal.

Wittgenstein nunca se interesó en describir los usos bilingües. Sordo a su propio consejo, él los curó en vez de describirlos. Observa, por ejemplo, que una de las cosas que puede "suceder" cuando uno trata de expresar una idea o un sentimiento al escribir una carta, es que uno piense en algo en un idioma extranjero y luego trate de interpretarlo a la lengua materna propia. Wittgenstein va muy rápido aquí de una cosa a la otra, como si fuese de una causa a su efecto inevitable. Se nos ha adelantado, saltando de un estímulo en inglés a su deseada respuesta en alemán, prácticamente colapsando los dos eventos en uno. Cuán extraña nos parece su impaciencia ante la interferencia; qué inesperadamente prescriptiva 
parece su meta monolingüe en Las investigaciones filosóficas, donde la tolerancia es el remedio para los "problemas filosóficos". "Mire y vea”, era su repetido consejo a los pensadores que habían perdido el contacto con el mundo. En lugar de teorizar sobre lo que se puede y no se puede hacer con el lenguaje, Wittgenstein se ocupa de hacer cosas con él, como, por ejemplo, escribir una carta.

Sin embargo, Wittgenstein parece estar estancado en por lo menos un parámetro abstracto de la filosofía del lenguaje, quiero decir, en su reducción de las funciones cotidianas a un sólo código lingüístico. El hecho que Wittgenstein pensara y se comunicara en más de un idioma (sospecho que muchos filósofos del lenguaje lo hacen), no parece haberle interesado. Con las puertas de la terapia monolingüe todavía cerradas, una expresión en inglés se le ocurre a Wittgenstein, y él actúa con indiferencia hacia la forma en que esto funciona. Apenas la mira, difícilmente la ve, y rápidamente la descarta para poder dar con un sustituto correspondiente en alemán. ¿Cómo se habrían podido desarrollar las Investigaciones si la cerca alrededor de las terapias monolingües se hubiera abierto? Seguramente considerarían el modo en el que un idioma funciona en asociación con otro. Un segundo idioma será, a lo mejor, tan limitado como el primero, pero de forma distinta, y - en ocasiones - de manera liberadora. Por ejemplo, una ventaja que el cambio de códigos lingüísticos tiene para Wittgenstein es que le permite la posibilidad de liberar el pensamiento para buscar otras palabras, palabras en inglés. El debería haber notado que estos hilos paralelos representan flexibilidad y sutileza, ya que tanto lamentaba lo que se pierde al menospreciar las redes complejas de comunicación. "Una vez que registremos los daños causados por propuestas reduccionistas nos sentiremos como si tuviéramos que reparar una telaraña con nuestros dedos” (Wittgenstein 106).

Los inmigrantes que se aferran a la red de su lengua materna cuando llegan a los Estados Unidos, no son necesariamente malagradecidos; son complicados. Algunos norteamericanos se ofuscan cuando oyen las lenguas particulares en espacios públicos (en la calle, bares, negocios, hospitales, etc.). Pero las personas desplazadas de otros países a menudo defienden su libertad de expresión viviendo con códigos dobles (o múltiples), muchas veces prologando su uso durante varias generaciones. Si después de cruzar la frontera se les presiona para que adopten la cultura del país anfitrión es muy probable que los inmigrantes más creativos doblen sus defensas. Se someten y vacilan, en un contrapunteo. Los juegos idiomáticos florecen bajo la presión, mientras que el encanto de las culturas tradicionales sobrevive en muestras póstumas de originalidad. La nueva creatividad políglota valora los encantos de las malas traducciones, los chistes con risa postergada, y la posibilidad de conmutar las reglas de una lengua por las de otra:

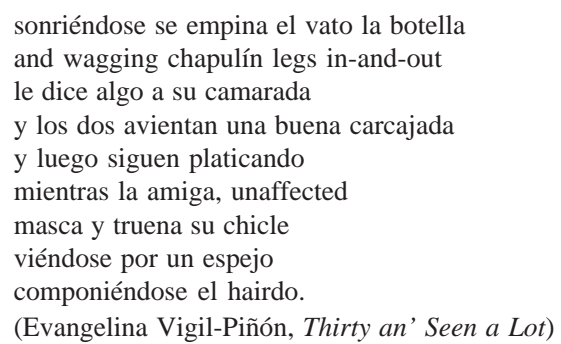


Los bilingües entienden la arbitrariedad del lenguaje aún con más intensidad que los teóricos que después de Paul de Man, llaman al lenguaje alegórico porque las palabras están en un orden diferente al de sus elusivos referentes. Más allá de lo elusivo, el lenguaje de todos los días puede ser opaco cuando enfrenta a otro, a veces intencionalmente opaco, como un recuerdo de la sobrevivencia de las diferencias culturales. "Nosotros tenemos derecho a nuestra opacidad” (Glissant). Así comienza el manifiesto para la autodeterminación cultural escrito por Edouard Glissant. ${ }^{9}$

Me gustaría considerar algunas prácticas que defiendan esta opacidad contra la normalización modernizante de la cultura. Son juegos bi o (multi-) lingües que se aprovechan de los residuos disonantes de la asimilación (o llevan errores intencionales y graciosos) después de que un idioma particular es forzado dentro de códigos universales. Las interrupciones, los retrasos, los cambios de código y la comunicación sincopada son aspectos retóricos del juego bicultural idiomático. A pesar de todo lo que podamos lamentarnos de los estragos que hace la modernidad sobre las diferencias culturales, sería incluso mucho más triste y contraproducente dejar que la lamentación ahogara los sonidos del contrapunteo cultural y de la supervivencia creativa.

Por supuesto que muchos escritores producen hoy para el mercado internacional, mientras que (según se quejan en los países anfitriones) la inmigración inunda las culturas nacionales. Un escéptico se preguntará si habrá suficientes lectores educados en el mercado nacional que quieran leer cosas más “auténticas”. Los motivos para quejarse son más que posibles de imaginar.

"Posibles pero no interesantes", es lo que le dijo el detective independiente de Borges al racional inspector de policía. Con este rechazo, el detective Eric Lonnrot en "La muerte y la brújula”, (1945) descarta la lógica del inspector, y la posible resolución inmediata del homicidio, a favor de una más interesante pero equivocada solución. Lonnrot termina teniendo más de un parecido con el proverbial Rabino quien responde a una obviamente correcta exégesis bíblica con desdén diciendo que "Esa es solamente una de las respuestas a la pregunta” porque generalmente las respuestas correctas olvidan mirar el inagotable misterio de los textos sagrados. Las soluciones posibles para resolver un homicidio, o las quejas justificadas contra la globalización, son respuestas poco creativas para enfrentar los retos que actualmente se nos presentan. Si el detective Lonnrot estuviera hoy presente, probablemente demoraría en sacar algunas conclusiones sobre la culpa o el daño con el fin de desarrollar preguntas más interesantes: a saber, ¿̇todo el mundo sufre daños? Cuando las víctimas incurren en una pérdida, ¿es total o hay factores mitigantes? Lonnrot habría observado, con un guiño, que dentro de la Argentina y de otros países latinoamericanos, donde los libros europeos y norteamericanos han sido lecturas accesibles y formadoras, igualmente prospera una fuerte tradición de literatura nacional. Los argentinos instruidos, que muchas veces aprenden a leer en inglés, o en francés, o en alemán, se reirían ante una

\footnotetext{
${ }^{9}$ En oposición a esto Henry Giroux sostiene que "politics of clarity... becomes a code word for an approach to writing that is profoundly Eurocentric in both context and content" (166). Della Pollock desarrolla su argumento en oposición a la costumbre de nivelar la relación entre el lenguaje y la audiencia, al descartar las demandas subalternas del lenguaje: "Claims for such writing assume a correspondence theory of language that effaces questions of voice, style and difference” (Phelan 73103).
} 
ansiedad casi provinciana de castidad lingüística. Seguramente han sentido la satisfacción de mirar cómo el mundo letrado por fin avanzó hacia la Argentina, el sur, donde ellos siempre han marcado su frontera. Allí, y en México, en Cuba, o en cualquier otro país de Latinoamérica (especialmente en Brasil), los patriotas saben que la economía y la educación les obliga a cruzar fronteras y lenguajes. Y la literatura más "auténtica”, puede ser irónicamente la más híbrida. Piénsese por ejemplo, en la novela escrita en ”cubano” por Cabrera Infante, Tres tristes tigres, donde Sam Clemens sigue a San Alfonso en la lista de los Filósofos Iluminados (269). El libro se abre con la divertida —e imperfectamente bilingüe- bienvenida a un club nocturno, que pudiera haber incluido unas cuantas ironías sobre un Primer Mundo que anda preocupado por la creatividad que se pierde en la traducción:

Showtime! Señoras y señores. Ladies and gentlemen. Muy buenas noches, damas y caballeros, tengan todos ustedes! In the marvellous production of our Rodney the Great! En la gran, maravillosa producción de nuestro GRANDE, Roderico Neyra! "Going to Brazil” Intitulada, “Me voy pal Brasil. Trarará, trarará, trarará tarará tarareo! Brazil terra dye nostra felichidade" That was Brazil for you, ladies and gentlemen. That is my very very particular version of it! en el idioma de Chakespeare, en English. (Cabrera Infante, 15)

Lonnrot, el detective de Borges, prefería jugar que ganar. Incluso después de que Lonnrot finalmente pierde, sus últimas palabras buscan ajustar las reglas del juego para continuar la siguiente partida en su otra vida. Podía haber cerrado el primer caso con una solución poco imaginativa; en cambio, prefirió abrirlo con preguntas absurdas que nos llevaron por un camino encantadoramente pavimentado de retos intelectuales. Si el caso se hubiera solucionado simplemente, no podría haber sido un vehículo para uno de los temas favoritos de Borges, el de la codependencia entre ley y crimen, detectives y delincuentes, signos y realidades. Lonnrot es seducido por la aventura hermenéutica que el asesino aparentemente le tiende como una trampa personal. Lonnrot, de hecho, “malconstruye” una evidencia de las circunstancias en un signo de invitación. Acepta la invitación, confiando que está por lo menos al mismo nivel que el de su presa. Su juego mortal comienza deletreando el sagrado e indecible nombre hebreo de Dios.

La historia del detective camina por las fallas del lenguaje oficial, en las gastadas conexiones que no resisten las incursiones de los códigos marginales. El derecho es un sistema que incluye a todos; es claro, uniformemente accesible, y por lo tanto indiferente a las distracciones extranjeras. Pero algunos hablantes, aburridos de la uniformidad, prefieren las distracciones. ¿Por qué repetir el tedioso juego de tener razón, si el de ser ingenioso es más divertido? Así que Lonnrot asume un lenguaje particularista de textos sagrados y comulga con su contrincante. Otra manera de entender el nexo a través del hebreo es que el lenguaje mismo, por ser extranjero, es el vehículo de comunicación especial entre los jugadores. No es que ese medio especial lleve a un choque con el idioma oficial. Aquí no pasa nada fuera de la ley, ni a pesar de ella, ni —Dios nos libre— en su contra. Después de todo, es Lonnrot quien ha defendido las leyes tan efectivamente que los mismos criminales lo designaron a él como su enemigo número uno. Pero el código jurídico es flojo en ciertos puntos; es tedioso o, en otras palabras, poco interesante cuando se le compara con 
la opción de un lenguaje particular que el derecho considera irrelevante. Gracias a la total indiferencia o desprecio por los signos extranjeros (“el inspector los consideró con miedo, incluso con repulsión”), los jugadores pueden a veces encontrarse sin vigilancia.

El asunto es que las perturbaciones extranjeras pueden ser flagrantes a propósito. Pueden ser la firma de un lenguaje particular a través de un medio universal. En la asimetría de recepción que ellos imponen, se abre un gran espacio para la estética y la experimentación social.

\section{BiBLIOGRAFÍA}

Amar Sánchez, Ana María. Juegos de seducción y tradición. Literatura y cultura de masas. Rosario, Argentina: Beatriz Viterbo, 2000.

Anderson, Benedict. The Spectre of Comparisons: Nationalism, Southeast Asia and the World. Londres/Nueva York: Verso, 1999.

Bhabha, Homi K. The Location of Culture. Nueva York: Routledge, 1996.

Borges, Jorge Luis. “Death and the Compass”. Everything and Nothing. Nueva York: New Directions, 1999.

Bourdieu, Pierre. The Rules of Art: Genesis and Structure of the Literary Field. Susan Emannuel, trad. Stanford: Stanford University Press, 1992.

Cabrera Infante, Guillermo. Tres tristes tigres. Barcelona: Seix Barral, 1967.

Cavell, Stanley. Must We mean What We Say? Cambridge: Cambridge University Press, 1976.

Degregori, Carlos Iván, "Panorama de la antropología en el Perú: del estudio del Otro a la construcción de un Nosotros diverso". No hay país más diverso: compendio de antropología peruana. Carlos Iván Degregori, ed. Lima: Red para el Desarrollo de las Ciencias Sociales en el Perú, 2000. 20-73

Du Bois, W. E. B. Souls of Black Folk [1903]. Three Negro Classics. Nueva York: Avon Books, 1965.

Freud, Sigmund "Wit and its Relation to the Unconscious”. The Basic Writings of Sigmund Freud [1905]. Translated and edited, with an introduction by Dr. A. a. Brill. Nueva York: The Modern Library, 1938.

Freyre, Gilberto. The Masters and the Slaves [Casa-Grande \& Senzala]: A Study in the Development of Brazilian Civilization. Samuel Putnam, trad. Nueva York: Alfred A. Knopf, 1946.

Fuentes, Carlos. La muerte de Artemio Cruz. México: Fondo de Cultura Económica, 1962. García Berumen, Frank Javier. The Chicano/Hispanic Image in American Film. Nueva York: Vantage Press, 1995.

García-Canclini, Néstor. La globalización imaginada. Buenos Aires: Paidós, 1999.

Gilman, Sander L. Jewish Self-Hatred: Anti-Semitism and the Hidden Language of the Jews. Baltimore: The Johns Hopkins University Press, 1986.

Giroux, Henry. "Language, Power and Clarity or 'Does Plain Prose Cheat'?” Living Dangerously: Multiculturalism and the Politics of Difference. Nueva York: Peter Lang, 1993.

Glissant, Edouard. Le Discours Antillais. París: Editions du Seuil, 1981. 
Jones-Correa, Michael. "Under Two Flags: Dual Nationality in Latin American and Its Consequences for the United States”. The David Rockefeller Center for Latin American Studies, Working papers on Latin America, Paper No. 99/00-3

Lloyd, David. “The Memory of Hunger”. Irish Hunger. T. Hayden, ed. Boulder, 1997.

Mignolo, Walter D. "Local Histories/Global Designs. Coloniality, Subaltern Knowledges, and Border Thinking”. Princeton: Princeton University Press, 2000.

Phelan, Peggy y Jill Lane (ed.). "Performing Writing". The Ends of Performance. Nueva York: New York University Press, 1998. 73-103.

Scott, Sir Walter. Ivanhoe [1819]. Nueva York: Airmont Classic, 1964.

Vigil, Evangelina. Thirty an’ Seen a Lot. Houston: Arte Público Press, 1982. Last section of "Por la Calle Zarzamora".

Wittgenstein, Ludwig. Philosophical Investigations. Oxford: Blackwell, 1998.

Zentella, Ana Celia. Growing up Bilingual. Malden, MA/Oxford: Blackwell, 1997.

Renan, Ernst. Qu'est-ce qu'une nation?= What is a nation. Wanda Romer, trad. Toronto, Ont.: Tapir Press, 1996. 